\title{
Catequesis y espiritualidad en el De uirtutibus sancti Martini episcopi, de Gregorio de Tours (siglo VI)*
}

\author{
Marcelo Aguirre Durán ${ }^{a}$ \\ Universidad de los Andes, Chile \\ http://orcid.org/0000-0002-6282-5847 \\ RECIBIDO: 18-07-19. APROBADO: 17-11-2019
}

Resumen: Durante la segunda mitad del siglo VI, el obispo Gregorio de Tours (573-594) redactó una compilación de cuatro libros de milagros realizados por la intercesión de San Martín, obra conocida como De uirtutibus sancti Martini episcopi. Este texto constituye una valiosa fuente para el estudio de la vida de la Iglesia en la antigua Galia merovingia, pues presenta al santo patrono de la diócesis de Tours como el modelo excelso de obispo e intercesor de los cristianos de la región. Por medio de un análisis de los relatos portentosos y de las características propias de la literatura hagiográfica de la Antigüedad tardía, el trabajo propone un estudio del sentido catequético-doctrinal del mencionado compendio de favores, los cuales son presentados al lector de la época como acontecimientos providentes que posibilitan un acercamiento a las dimensiones personal y comunitaria de la vida cristiana. De este modo, la narración pastoral ejemplifica de manera física y sobrenatural cómo los fieles que llegaban a la tumba-santuario de la ciudad del Loira experimentaban la conversión del alma y, conforme a ello, la acción prodigiosa de Dios. Gracias a la intercesión del santo protector de Tours, el relato expone de manera pedagógico-moral el valor de la oración privada, de la penitencia individual y de la puesta en práctica de los ideales ascéticos. Así, la narración literario-pastoral del prelado galorromano Gregorio pone el acento en la acción divina de los milagros, los que constituyen el resultado de un proceso interior que culmina con la compunción del alma, que nace de una sincera humildad cristiana, virtud fundamental para la ascensión espiritual de los bautizados que siguen el ejemplo de san Martín.

Palabras Clave: Gregorio de Tours; San Martín de Tours; Galia; siglo VI; hagiografía; milagro; catequesis; conversión.

*Artículo de investigación.

${ }^{a}$ Autor de correspondencia. Correo electrónico: marceaguirred@gmail.com 

(6th Century)

АвsтRACT: During the second half of the 6th Century, Bishop Gregory of Tours (573-594) wrote a compilation of four books of miracles performed through the intercession of Saint Martin, a work known as De uirtutibus sancti Martini episcopi. This text is a valuable source for the study of the life of the Church in Antique Merovingian Gaul, as it presents the Patron Saint of the diocese of Tours as the exalted model of a bishop and intercessor for the Christians of the region. By means of an analysis of the portentous stories and of the characteristics proper to the hagiographical literature of Late Antiquity, this work proposes a study of the catechetical and doctrinal sense of the above-mentioned compendium of favours, which are presented to the reader of the time as providential events that make it possible to approach the personal and community dimensions of Christian life. In this way, the pastoral narrative exemplifies in a physical and supernatural way how the faithful who arrived at the sanctuary of the city of the Loire experienced the conversion of the soul and, consequently, the prodigious action of God. Thanks to the intercession of the Patron Saint of Tours, the story illustrates in a pedagogical and moral way the value of private prayer, individual penance and the implementation of ascetic ideals. Thus, the literary and pastoral narrative of the Gallo-Roman prelate Gregory emphasises the divine action of miracles which are the result of an inner process that culminates in the compunction of the soul, which is born of sincere Christian humility. The latter is a fundamental virtue for the spiritual ascension of the baptised who follow the example of St. Martin.

Key Words: Gregory of Tours; Saint Martin of Tours; Gaul; 6th Century; Hagiography; Miracle; Catechesis; Conversion.

\section{CÓMO CITAR:}

Aguirre Durán, Marcelo. "Catequesis y espiritualidad en el De uirtutibus sancti Martini episcopi, de Gregorio de Tours (siglo VI)". Theologica Xaveriana (2021): 1-24. https://doi. org/10.11144/javeriana.tx71.cedusme

\section{ReCONOCIMIENTO}

El presente estudio forma parte del proyecto de investigación N. ${ }^{o} 1170661$ (2017-2020), financiado por el programa Conicyt-Fondecyt (Chile). 
Los modelos tipológicos plasmados en la hagiografía latino-cristiana de la segunda mitad del siglo VI representan una sociedad en la cual las figuras ascéticas de los uiri y amici Dei se tornan fundamentales, pues ellas representan los ideales de una vida evangélica y de una acción pastoral centrada en la aedificatio ecclesiae de sus días.

En este contexto religioso-cultural, la fisonomía del cristianismo tardo antiguo aparece configurada y orientada por un conjunto de santos quienes, por numerosos milagros, sirven de referentes doctrinales y morales para las comunidades cristianas que los adoptan como patrones y protectores'. Para el caso concreto de la Galia merovingia, tema de nuestro trabajo, el epítome de esta santidad ha sido, a partir del siglo V, la figura de San Martín de Tours², asceta y obispo que se transformó en un verdadero "fenómeno nuevo"3 de la literatura hagiográfica galorromana de este periodo, lo cual redundó en una veneración ampliamente difundida gracias al rápido desarrollo del santuario-basílica de la ciudad Tours ${ }^{4}$.

Un particular testigo y protagonista de estos acontecimientos fue el obispo Gregorio, consagrado en dicha diócesis en el año 573. El conjunto de su obra hagiográfica, resumida por él mismo al final de la Historia francorum, se compone de siete libros de milagros referidos a santos varones ${ }^{5}$, cuatro de los cuales están dedicados a San Martín -De uirtutibus sancti Martini episcopi-6 ${ }^{-6}$ los que constituyen una nutrida recopilación de los portentos posmortem realizados por el santo, sobre todo aquellos obrados en las distintas peregrinaciones de los fieles a la basílica de la ciudad del Loira.

${ }^{1}$ Véase a Dumézil, "Des évêques locaux aux saints civiques en Gaule"; Van Dam, Saints and their Miracles in Late Antique Gaul.

${ }^{2}$ San Martín (†397), considerado el apóstol de las Galias, sirvió en el ejército romano y después de su conversión tuvo una primera experiencia eremítica en la isla de Gallinara. Vivió bajo el ascetismo monástico en Ligugé, en las cercanías de Poitiers, y luego en Marmoutier, junto al río Loira. Fue consagrado obispo de la diócesis de Tours en 371. Al respecto véase a Jacques Fontaine (ed.), Sulpice Sévère. Vie de Saint Martin I, en particular el Capítulo 4 de la Introducción.

${ }^{3}$ Judic, "Les origines du culte de Saint Martin de Tours aux Ve et VIe siècles", 4-8.

${ }^{4}$ El obispo Perpetuo, antes del año 467, edificó una basílica para propiciar la devoción a las reliquias de San Martín. Para una evolución de este culto, véase a Pietri, La ville de Tours du IVe au VIe siècle. Naissance d'une cité chrétienne, 731-786; Rousselle, Croire et guérir. La foi en Gaule dans l'Antiquité tardive, 109-122.

${ }^{5}$ Heinzelmann, "La réécriture hagiographique dans l'œuvre de Grégoire de Tours", 16.

${ }^{6}$ El conjunto de la obra de Gregorio de Tours se encuentra en la colección MGH, bajo la edición de Bruno Krusch. Para el caso del Vitae Patrum, hemos utilizado la edición latino-francesa de Les Belles Lettres. La traducción de los textos al español es nuestra. 
Esta colección detallada de prodigios realizados gracias a la virtud del intercesor, escrita a lo largo de todo el episcopado de Gregorio ${ }^{7}$, nos presenta una Iglesia en la cual la acción divina se manifiesta por medio de los hombres de Dios, quienes resumen en sí las virtudes cristianas, la experiencia espiritual de los bautizados y, en gran medida, las características propias del ascetismo y del camino hacia la conversión verdadera.

\section{Relato ejemplar y enseñanza doctrinal}

La literatura hagiográfica latino-cristiana y su correspondiente narración compendiada de milagros es, en la mayoría de los casos y tal como lo ha propuesto el profesor belga Guy Philippart, una literatura ejemplar ${ }^{8}$ que en la época no logra distinguirse del sentido propio de la historia secular?. Este aspecto resulta particularmente evidente si se trata de la devoción a la figura de un santo protector como San Martín ${ }^{10}$, modelo tipológico de asceta y de pastor de la comunidad eclesial turonense. Por eso, la proximidad a la figura del santo y su presencia en la cotidianeidad de una diócesis aparece reflejada con características particulares que permiten dar unidad pastoral al conjunto de milagros llevados a cabo en la basílica de Tours y recogidos por el obispo Gregorio ${ }^{11}$.

A partir de un análisis de los textos se puede observar que el objeto de este autor galorromano de poner por escrito los portentos acaecidos sería, principalmente, narrar bajo categorías laudatorias y para memoria de los fieles cristianos algunos de los numerosos milagros obrados por el santo de la ciudad y, de este modo, catequizar y educar en las verdades de la fe a los creyentes por medio de las experiencias espirituales derivadas de los testimonios historiados. Por ello, la función didáctica del portento divino se encontraría asociada, en este caso, a un sentido teológico-pastoral

7 El De uirtutibus sancti Martini episcopi fue escrito a partir del 573. Los cuatro libros tienen una estructura independiente y el último terminaría abruptamente, poco antes de la muerte del autor. Un total de 201 milagros son atestiguados, recopilados y narrados por el obispo de Tours, además de una introducción que sitúa al lector en su proyecto hagiográfico-pastoral. Para la cronología, véase a Pietri y Heijmans, Prosopographie chrétienne du Bas-Empire. Prosopographie de la Gaule chrétienne (314-614), I, 922-948.

8 Philippart, "L'hagiographie, histoire sainte des amis de Dieu", 31.

9 Labarre, "La figure de Saint Martin chez Grégoire de Tours", 212.

${ }^{10}$ Beaujard, Le culte des saints en Gaule, 333-398; véase también a Pietri, "Quand et comment Martin de Tours est-il devenu le saint patron par excellence de la Gaule?".

${ }^{11}$ Las hagiografías, en cuanto vidas, tienen una dimensión espacial que pretendería ser universal. El recuento de milagros, por su parte, atiende más bien a la acción concreta en un tiempo de terminado y que trasciende por la devoción profesada por el pueblo a aquel que es el protector. 
y, al mismo tiempo, al deseo de alabar a Dios por medio de la veneración devota a San Martín, el pontífice e intercesor por excelencia ${ }^{12}$.

Esta proximidad con el santo representa una alabanza a Dios en sí misma, pues la experiencia real de la acción divina en el devenir cotidiano del fiel se expresa en el milagro y en una lectura de dicho acontecimiento como una suerte de anagogía del prodigio, en la que el santo aparece como quien une a la comunidad con Cristo en cuanto amicus Dei'is.

En este punto es posible afirmar que los cuatro libros del De uirtutibus sancti Martini episcopi corresponderían no solo a una antología de acontecimientos maravillosos, sino al mismo tiempo, a una catequesis de la vida interior operada por medio de acciones exteriores taumatúrgicas tales como las curaciones y las sanaciones físicas reiteradas ${ }^{14}$. En otros términos, lo que a primera vista parecería ser una simple e incluso ingenua enumeración detallada de milagros relatados por el obispo Gregorio correspondería, de una u otra forma, a lo que podríamos considerar como una suerte de teología espiritual que iría más allá de la simple narración retórica.

Esta catequesis del testimonio no pretendería una explicación compendiada del dogma, sino más bien una inserción en "la historia de la salvación que tiene por objetivo enseñar al catecúmeno lo que es la identidad cristiana o, quizás mejor, la ciudadanía cristiana” ${ }^{15}$. Así, el sentido de este compendio permitiría entender que, por medio de cada prodigio obrado a partir de la contrición del creyente, se hace presente una edificación de la Jerusalén celeste en la tierra, en donde las gestas providenciales operadas en el tiempo constituirían una expresión consciente de la dulzura y de la suavidad divinas ${ }^{16}$, propias de la concepción de una historia santa, así como de una función paternal y protectora de la enseñanza evangélica.

Dicha visión supone una premisa que es ante todo una cuestión fundamental a la hora de aproximarse a los textos de corte hagiográfico de los autores de la época

\footnotetext{
${ }^{12}$ Heinzelmann, "Grégoire de Tours et l'hagiographie mérovingienne", 165.

${ }^{13}$ Beaujard, Le culte des saints en Gaule. Les premiers temps. D'Hilaire de Poitiers à la fin du Vie siècle, 272; Boesch Gajano, "Spazi del meraviglioso nell'alto medioevo latino", 24-25.

${ }^{14}$ La dimensión catequético-narrativa de la obra entiende el testimonio y el portento como una experiencia espiritual, algo propio de la tradición de la Iglesia a lo largo de los siglos. A modo de ejemplo, en el número 100 de los Ejercicios Espirituales, San Ignacio sugiere el mucho provecho de la lectura de la vida de los santos, lo que también supondría la ejemplaridad de sus milagros.

${ }^{15}$ Madec, Saint Augustin. La première catéchèse (De catechizandis rudibus), 30.

${ }^{16}$ Giuseppe Cremascoli, a propósito de Gregorio Magno, retoma lo escrito por Adalbert de Vogüé en la introducción al libro de los Diálogos: “...les miracles font goûter la douceur de Dieu”. Véase a De Vogüé, Grégoire le Grand. Dialogues I, 48.
} 
tardo-antigua y alto-medieval: ellos desean ser hombres fieles a la Iglesia ${ }^{17}$. Esto conllevaba de manera inherente una ortodoxia doctrinal y un deseo pastoral de formación de la comunidad a su cargo.

Por ello, en el conjunto del relato de Gregorio, así como en el mundo que él intenta reflejar, la intervención divina aparece de manera incesante en el orden natural, por medio de las personas elegidas. Los prodigios obrados por los santos dan lugar a las enseñanzas de la doctrina y de la verdadera fe y sus testimonios hacen posible, de forma cotidiana y a la vez tácita para el común de los cristianos, los principios evangélicos y la peregrinatio del creyente; en palabras de Martin Heinzelmann: "La reescritura del milagro se convierte también en instrumento de Cristo" ${ }^{18}$.

De este modo, el concepto "expresión de lo divino" ${ }^{19}$ reflejado en la comunidad turonense del siglo VI permitiría comprender que la intervención de Dios, realizada mediante las gestas maravillosas atribuidas a los santos, representa una enseñanza catequética y tiene un sentido cristológico último ${ }^{20}$.

En otras palabras, podríamos decir que al aproximarnos a la lectura de los milagros de San Martín estaríamos frente a variadas formas que apuntarían a una función apologética o estrictamente ejemplar y, al mismo tiempo, irían de la mano de una manifestación de la realidad de la Iglesia celeste; y que esta se mostraría de manera más o menos constante por medio de los signos visibles de sanaciones y curaciones físicas y también morales; es decir, una suerte de destellos de la luz divina en la historia de la salvación.

En el mismo orden de cosas, es el propio Gregorio quien en el Prefacio a su obra hagiográfica dedicada a los ascetas de la Galia -Vitae Patrum- escribe: “...sus méritos y sus poderes son diversos, sin embargo, para todos es una única vida” ${ }^{21}$. La vida en Cristo aparecería, entonces, como la verdadera vida del cristiano encarnada en el ejemplo de los grandes hombres de su tiempo.

En consecuencia, la santidad de San Martín se insertaría en un relato histórico general en el cual los hombres de Dios aparecerían prefigurando esa patria celeste que se entendería a partir de la idea del cuerpo místico y de la comunidad de los

${ }^{17}$ Peter Brown propone esta idea también para Gregorio de Tours (Brown, Through the Eye of a Needle. Wealth, the Fall of Rome, and the Making of Christianity in the West, 350-550 AD, 498).

${ }^{18}$ Heinzelmann, "Grégoire de Tours et l'hagiographie mérovingienne”, 183.

${ }^{19}$ Labarre, "Lexpression du divin dans l'hagiographie de Venance Fortunat et de Grégoire de Tours”, 37-56.

${ }^{20}$ Aguirre Durán, "Gregorio de Tours y la hagiografía del siglo VI. Aproximaciones histórico-teológicas al libro Sobre las virtudes de San Martín”, 302.

${ }^{21}$ Gregorio de Tours, Liber Vitae Patrum, Prefacio: "cum sit diuersitas meritorum uirtutumque, una tamen omnes uita". 
$\operatorname{santos}^{22}$, donde "los pobres, los monjes, los santos y los sacerdotes que ofrecían la eucaristía en nombre de los fieles eran todos ellos -cada uno de manera distintaconsiderados intercesores" ${ }^{23}$.

\section{La dinámica de la penitencia y la oración en torno a los milagros}

A partir de la lectura hagiográfica de los portentos de San Martín podemos señalar que la narración de los cuatro libros de los milagros se enmarca en un programa general en el que primaría un sentido orgánico interno, el cual se encontraría orientado hacia una edificación de la comunidad y del fiel en particular, bajo un esquema que podría ser entendido de la siguiente manera:

- Un primer acto de búsqueda del silencio exterior.

- Un alejamiento del mundo y un posterior acercamiento a la basílica o a alguna reliquia del santo (o sea, una presencia sensible del mismo).

- Un silencio interior propio del recogimiento del alma el cual, unido a la acción de la oración privada, se manifiesta como un anhelo profundo de una curación que presupone el arrepentimiento y que se conjuga con el mérito obtenido por la penitencia.

Una vez ocurrido lo anterior, Gregorio propicia la aparición del milagro que, en su carácter de intervención divina en lo humano, estimula a los otros cristianos al seguimiento de Cristo y a una fidelidad al bautismo ${ }^{24}$. Esta dinámica espiritual de arrepentimiento y sanación aparece representada de manera más o menos explícita en la casi totalidad de los prodigios narrados, lo que respondería a este proyecto catequético-testimonial propuesto por el obispo de Tours por medio de los milagros de San Martín.

A propósito, entre los numerosos relatos que pueden ilustrar esta idea encontramos la historia de Bella, una ciega que se dirigió al santuario con la ayuda de un guía, y una vez allí, "persistiendo en los ayunos y en las frecuentes oraciones, mereció recobrar la vista que había perdido" 25 . En este mismo sentido se nos narra el caso del

${ }^{22}$ Labarre, "L'expression du divin dans l'hagiographie de Venance Fortunat et de Grégoire de Tours", 44; Heinzelmann, "Grégoire de Tours et l'hagiographie mérovingienne", 166.

${ }^{23}$ Brown, Through the Eye of a Needle. Wealth, the Fall of Rome, and the Making of Christianity in the West, 350-550 AD, 516.

${ }^{24}$ Guy Philippart explica el sentido estimulante de la narración hagiográfica (Philippart, "L'hagiographie, histoire sainte des amis de Dieu”, 25).

${ }^{25}$ Gregorio de Tours, De uirtutibus sancti Martini episcopi, I, 19: “...ibique ieiuniis et orationibus crebris insistens, uisum, quem amiserat, recipere meruit". 
niño que padecía una enfermedad que le impedía caminar; él pidió a sus padres ser llevado al santuario de San Martín y allí, tras jornadas de plegarias y penitencias, fue curado: “...al tercer día él y sus padres persistían en las oraciones y ayunos; cuando la luz divina apareció, las piernas se desentumecieron y el niño fue devuelto sano a su familia" ${ }^{26}$.

Cabe señalar que el pretérito del verbo merecer (meruit) denotaría una acción del cristiano que desencadenaría el favor divino, es decir, únicamente por medio de la oración y de la penitencia ejercitada por el fiel cristiano se podría llevar a cabo el milagro divino, pues este se daría como respuesta de Dios a la contrición demostrada por el hombre, respuesta obrada por medio del santo.

En definitiva, la enseñanza aparecería más o menos clara para el lector del texto pues, en otros términos, por medio de los ejemplos de sus contemporáneos se explicitaría cómo la curación física iría siempre acompañada de un proceso de purificación del espíritu y de curación del alma; esta última, en la mayoría de los casos, aparecería representada a través del reconocimiento y la alabanza a Dios.

Teniendo en consideración lo recién expuesto, el retiro que suponen los días de ayuno y plegarias - habitualmente tres- tendría también un sentido cristológico manifestado en la obra del obispo Gregorio, lo que ha sido magistralmente estudiado por Martin Heinzelmann para el conjunto del corpus gregoriano ${ }^{27}$. En consecuencia, podríamos afirmar que el milagro vendría a ser el resultado de una conversión de vida incoada en los primeros pasos de devoción al santo en su santuario, es decir, en una iniciación cristiana que se manifiesta públicamente por la adhesión a la fe, tal como se refleja en la curación del ciego Orsoulfo, hombre de la ciudad de Tours quien, una vez sanado en su cuerpo y en su espíritu, "se dignó dedicarse al servicio de aquel que le había hecho, por así decirlo, renacer al mundo una segunda vez" ${ }^{28}$.

Por tanto, el fiel que recibe el favor divino se transforma él mismo en un testimonio encarnado de la dimensión sobrenatural, pues ya no solo se constituye en el beneficiario del milagro, sino que así mismo actúa como catalizador de la virtud del santo en la tierra, en este caso San Martín, quien se muestra dadivoso con los cristianos fieles que se han convertido a las promesas del bautismo. Entonces, quien recibe el favor divino es, al mismo tiempo, el testimonio visible de la perfecta caridad del intercesor celeste, que ya goza de la visión beatífica.

${ }^{26}$ Ibíd., III, 6: “...tertia uero die cum ille uel parentes eius in oratione ac ieiunio perdurarent, exorto misericordiae lumine, distortis tibiis, a parentibus incolomis est receptus".

${ }^{27}$ Cfr. Heinzelmann, "La réécriture hagiographique dans l'œuvre de Grégoire de Tours".

${ }^{28}$ Gregorio de Tours, De uirtutibus sancti Martini episcopi, II, 13: “...et ad suum dignatus est dicare seruitium, quem, ut ita dicam, renasci denuo fecit in mundo". 
Sumado a lo anterior, cabe indicar que el sentido del milagro adquiriría una significación particular de acuerdo con la lectura personal del sujeto que es favorecido y, así mismo, un sentido comunitario, pues el fiel sanado también sería testimonio presente en medio de la iglesia local que atestiguaba, con una naturalidad cotidiana, la acción divina en sus días ${ }^{29}$.

En esta misma perspectiva encontramos el relato de la sanación del enajenado Aquilino, quien desde lejos fue llevado a la basílica de San Martín por sus progenitores; una vez allí, "se entregaron a la oración y viviendo con la mayor humildad demandaban asiduamente el auxilio del santo" ${ }^{30}$. Después de mucho tiempo, gracias a la fe manifestada, "él recobró el sentido que había tenido anteriormente y, habiendo dejado a sus padres, se unió, gracias al beneficio que había recibido, al servicio de este lugar donde aún hoy se encuentra" ${ }^{31}$.

Por ello nos atrevemos a afirmar que Gregorio entiende que la curación no es solo un asunto individual sino la manifestación de Dios a un hombre, pero también a una comunidad cristiana, en este caso la turonense.

Dicho reconocimiento del bien se hace presente y queda como testimonio espiritual de la creación divina restaurada por medio de la gracia de Dios, administrada por el santo y renovada por medio de la reparación hecha por la falta cometida, tal como se cuenta en el relato de la salvación de un condenado a muerte quien, al ver acercarse su deceso, pidió tiempo para rezar e imploró por el perdón de sus pecados y, dos días después de estar suspendido sin haber muerto, fue liberado de su condena por intercesión de San Martín.

Esto, en palabras de Gregorio, se resume del siguiente modo: "Yo no observo el milagro manifestado en este hombre, es decir, que el bienaventurado confesor lo hubo arrancado de los dientes de la muerte y reintegrado a la vida, como menor que haber resucitado a un muerto" ${ }^{2}$. Y más adelante agrega: "Aún hoy vive en el mundo como un testimonio de la virtud del santo" ${ }^{33}$.

\footnotetext{
${ }^{29}$ Sobre el lugar y el poder del milagro en la Galia merovingia, véase a Heinzelmann, "Pouvoir et idéologie dans l'hagiographie mérovingienne", 49-51; Van Dam, Saints and their Miracles in Late Antique Gaul, 116-149; Rousselle, Croire et guérir. La foi en Gaule dans l'Antiquité tardive, 187-208.

${ }^{30}$ Gregorio de Tours, De uirtutibus sancti Martini episcopi, I, 26: “...ibique in oratione cum summa parcitate se contenens, opem sancti poscebat assiduae".

${ }^{31}$ Ibíd.: “... sensum, ut habuerat ante, recepit, oblitisque parentibus, in eo loco usque hodie pro beneficio accepto deseruit".

32 Ibíd., I, 21: “....non inferiorem censeo quam mortuum suscitatum; quem sic beatus confessor, ut ita dicam, confracto mortis hiatu, et eius ab ore retractum uitae restituit".

${ }^{33}$ Ibíd.: “...qui usque hodie ad testimonium uirtutis beati uiri uiuus habetur in saeculo”.
} 
En consecuencia, esta purificación y nueva vida asociada al milagro pone el acento en la idea de la justicia divina por medio del hombre de Dios, la que asociada a la caritas christiana siempre resulta "clara, rápida y sorprendentemente blanda" ${ }^{4}$, pues emana de Cristo y no de la humanidad. Por esto, el carácter taumatúrgico nos permitiría afirmar que Gregorio, de acuerdo con el sentir de su época, enseña cómo el cuerpo, en cuanto templo del Espíritu, reconoce el bien por medio de la sanación y padece el mal por medio del dolor asociado a alguna desobediencia.

Así se muestra en el caso de un hombre llamado Amonio quien, después de haber bebido vino en exceso, sufrió un accidente y escapó del peligro de la muerte pero quedó con un pie herido; luego, "habiendo venido a la tumba del glorioso señor Martín y habiéndose entregado allí a la oración, sintió cómo el dolor se calmaba completamente" ${ }^{35}$.

De igual modo, habría que suponer que el lector de los milagros redactados por el letrado Gregorio tiene una formación religiosa que le permite entender dichos relatos bajo una dimensión catequética y testimonial, como muestras de una pedagogía divina en la que el modelo del hombre de Dios constituye el ejemplo a imitar por parte del fiel cristiano. De hecho, y tal como lo comentamos anteriormente en relación con la oración personal y el arrepentimiento, el camino de purificación por medio de la ascesis aparece como un aspecto connatural de la peregrinatio christiana.

Así, por ejemplo, los relatos del hombre que fabricaba una llave y del campesino que hacía una cerca, ambas acciones realizadas en domingo, atestiguan el castigo a la desobediencia y el consiguiente impedimento físico de las manos, extremidades utilizadas en la profanación dominical. El tiempo pasado bajo estas condiciones de invalidez física enseñan al cristiano de qué manera el desorden del pecado se manifiesta en el cuerpo y luego, una vez arribada la contrición y situados en la basílica, en medio de la oración y de los ayunos, se logra la curación por intercesión del santo.

El primer hombre, "después de haberse entregado a la oración y a los ayunos durante cuatro días, elevó sus manos ya sanadas y se retiró curado, alabando el poder del pontífice y advirtiendo a cada uno de no intentar aquello que él había hecho" ${ }^{36}$; el segundo, por su parte vino a la basílica del santo, rogó y fue sanado. Él proclamó entonces, delante del pueblo, que nadie debía imitar lo que él había hecho: que un

\footnotetext{
${ }^{34}$ Brown, El culto a los santos. Su desarrollo y su función en el cristianismo latino, 213.

${ }^{35}$ Gregorio de Tours, De uirtutibus sancti Martini episcopi, I, 20: “...veniens ad gloriosi domni templum, orationi incumbens, omnem uim doloris amisit".

${ }^{36}$ Ibíd., III, 7: “...per quattuor dies oratione ac ieiunio vacans, manus sanas eleuans, incolomis est regressus, conlaudans uirtutem antistitis; et, ut nullus adgrederetur quod ipse praesumpserat, praedicabat".
} 
avaricioso labrador no debía profanar la solemnidad de un día tan grande [domingo], y que la humanidad dañada no debía perder el fruto del misterio celeste de la resurrección santa y de nuestra redención haciendo obras terrenales. ${ }^{37}$

De esta forma, el sentido último de la narración hagiográfica gregoriana se transparenta de un modo teológicamente unitario ${ }^{38}$, haciendo asequible la enseñanza de los misterios divinos y del ejemplo de vida por medio de los testimonios de los sanados. El primero alababa a Dios y advertía a los cristianos, mientras que el segundo enseñaba los misterios de la resurrección divina y de la redención de la humanidad y, por consiguiente, el carácter solemne del domingo, que es superior a las obligaciones de esta tierra.

Consecuentemente, no solo el testimonio oral, sino también la acción misma en el día del Señor, sirven de programa y modelo catequético para Gregorio, quien no deja de hacer notar cómo muchos de los milagros se dan en el día de reposo, siempre con un sentido cristológico, como aquel de la mujer muda quien, en el atrio del santuario de San Martín, permaneció días pidiendo limosna e implorando a Dios. Durante la misa del domingo ella pudo expresarse por primera vez en medio de la oración comunitaria, pasando de una padecida esclavitud física a la libertad del espíritu que se manifestaba en la proclamación de alabanzas por lo obrado en su persona:

...mientras se rezaba la oración dominical sucedió que ella comenzó a cantar a plena voz junto a los otros. Estaba encadenada bajo el yugo de la esclavitud, fue redimida por el bienaventurado confesor y ahora es libre y persevera en el oficio de la Palabra. ${ }^{39}$

Particularmente ilustrador resulta el milagro obrado en un hombre venido de Anjou, paralizado de pies y manos, quien "había estado allí toda la Cuaresma, rezando y suplicando a fin de que la virtud del santo pontífice le visitase" ${ }^{\text {"40. Llegado el }}$ domingo de la entrada de Jesús en Jerusalén previo a la Pascua, después de haber caído en un éxtasis de horas y estando como muerto, despertó curado y, después de pasar la noche en vela agradeciendo a Dios, testimonió este milagro y se hizo clérigo. En otras

\footnotetext{
${ }^{37}$ Ibíd., III, 29: “. . . ad basilicam sancti aduenit; oratione quoque facta, sanatus est, praedicans populis, ne factum quis meditaretur, ne tanti die solemnia auarus agricola macularet, ne redemptionis sacrae resumptionis nostrae caeleste mysterium humanitas infirma, terrena exercens opera, dissolueret".

${ }^{38}$ Heinzelmann, “The Works of Gregory of Tours and Patristic Tradition”, 333.

${ }^{39}$ Gregorio de Tours, De uirtutibus sancti Martini episcopi, II, 30: “...factum est autem, cum dominica oratio diceretur, et haec aperto ore sanctam orationem coepit cum reliquis decantare. Ipsa autem cum iugo seruitutis haberetur uincta, de rebus beati confessoris redempta est et nunc cum uocis officio ingenua perseuerat".

${ }^{40}$ Ibíd., II, 33: “...ubi cum tota quadragisima resedisset, assidue orans ac depraecans, ut eum uirtus sancti antistitis uisitaret”.
} 
palabras, el hombre sanado rechazó el mal del pecado y por medio de la purificación penitencial se volvió un testimonio viviente de Cristo, quien hubo obrado el milagro por medio de San Martín.

En vista de ello, la sacralidad del domingo y el carácter cristocéntrico de este día aparecen reflejados como cuestión fundamental a lo largo de los cuatro libros sobre los milagros escritos por Gregorio. A modo de ejemplo, es San Martín quien aparece como el epítome de ese carácter cristológico del primer día de la semana pues $^{41}$, al comenzar el libro I, nuestro autor nos cuenta que este santo murió in pace, en medio de la noche ${ }^{42}$, como símbolo de la paz del Cielo representada en el domingo, anticipación de la eternidad celeste que, como una suerte de prefiguración profética, da cuenta y anuncia con música angélica la entrada triunfal del protector turonense: “los ángeles cantando lo llevan a los cielos” ${ }^{3}$; “el coro de los ángeles brilla, el ejército de las virtudes celestes asiste" ${ }^{\prime 4}$.

Así mismo, en su Historia francorum agrega: “...en su tránsito muchos escucharon un canto en el cielo" ${ }^{45}$. Parecería claro entonces que, en su proyecto pastoral, la enseñanza por medio del ejemplo del bienaventurado San Martín simboliza de modo insigne la concreción de una vida fundada en Cristo, según las enseñanzas evangélicas, al modo de San Pablo en su Carta a los Gálatas (Ga 2,20).

\section{Humildad, ascesis y sabiduría de Dios}

La humildad, una de las mayores virtudes destacadas por las biografías sobre San Martín ${ }^{46}$, también tiene un lugar preponderante en el De uirtutibus sancti Martini episcopi, escrito por Gregorio, pues ella aparece como aspecto esencial de la aedificatio christiana que se propone por medio de la función pedagógico-evangelizadora del milagro. La humilitas evangélica constituye el fundamento de la ascensión espiritual, pues ella permite la cúspide de la vida religiosa, es decir, la visión de $\operatorname{Dios}^{47}$.

${ }^{41}$ Aguirre Durán, "Gregorio de Tours y la hagiografía del siglo VI. Aproximaciones histórico-teológicas al libro Sobre las virtudes de San Martín”, 303.

${ }^{42}$ Gregorio de Tours, De uirtutibus sancti Martini episcopi, I, 3: “...nocte media quieuit in pace”.

${ }^{43}$ Ibíd., I, 4: “...nunc angeli canendo eum deferunt in excelsum”.

${ }^{44}$ Ibíd., I, 5: “...angelorum exultat chorus, omnium que caelestium uirtutum occurrit exercitus”.

${ }^{45}$ Gregorio de Tours, Historiarum libri X, I, 48: “...multi enim in eius transitum psallentium audierunt in caelum".

${ }^{46}$ Nos referimos a las Vidas escritas por Sulpicio Severo, Paulino de Périgueux y Venancio Fortunato.

${ }^{47}$ Bouyer, Le sens de la vie monastique, 43: “...toda la Antigüedad cristiana comprendió la vocación del hombre como una vocación a compartir la vida angélica, en cuanto esta se define por la visión de Dios”. 
La verdadera humildad, antítesis de la vanagloria, ilumina a la Iglesia por medio de la grandeza del santo ${ }^{48}$, quien transmite la luz de Dios y propicia un acceso a la sabiduría divina por medio de la contemplación y no solo de los saberes seculares de las letras clásicas ${ }^{49}$. La virtud de la humildad del hombre de Dios, en este caso Martín, dota al milagro de una connotación que va más allá de la mera acción curativa y él deviene en una herramienta para el conocimiento divino pues -tal como lo ha afirmado Guy Philippart- este consiste en la confesión de la fe y en el testimonio hasta el final, al modo de los mártires ${ }^{50}$.

Para Gregorio de Tours, San Martín sería la concreción de esta sabiduría representada por medio del testimonio cristiano de los primeros siglos pues -en sus propias palabras- "soportó triunfalmente el martirio resistiendo, o bien las secretas asechanzas, o bien las agresiones públicas" ${ }^{51}$. Esta humildad del intercesor es explicitada desde el Libro I, pues se quiere dejar en claro que el santo del Loira no tuvo otras alabanzas más que para Dios: “...él es su propio elogio, este hombre que nunca se alabó a sí mismo"s2.

En cualquier caso, su perfecta humildad resulta la mejor loa no hacia él mismo sino hacia Cristo, quien es el verdadero autor de los acontecimientos milagrosos. De allí que la labor de Gregorio adquiera ribetes catequéticos con un sentido moral y espiritual, los que impregnan un relato que excedería la mera narración dinámica de los portentos para acercarse, a partir de un sentido espiritual, a un contexto con un claro contenido teológico ${ }^{53}$.

Ahora bien, aunque la figura de San Martín de Tours es presentada a partir de su labor protectora en calidad de obispo de la ciudad, consideramos que el sentido ascético-moral es un aspecto que debe ser tenido en cuenta a la hora de aproximarse a esta fuente hagiográfica. El carácter cristológico del compendio de milagros ${ }^{54}$

\footnotetext{
${ }^{48}$ Labrousse, Saint Honorat. Fondateur de Lérins et évêque d'Arles, 71.

${ }^{49}$ Heinzelmann, "Studia sanctorum. Éducation, milieux d'instruction et valeurs éducatives dans l'hagiographie en Gaule jusqu'à la fin de l'époque mérovingienne”, 109.

${ }^{50}$ Philippart, "L’hagiographie, histoire sainte des amis de Dieu", 31.

${ }^{51}$ Gregorio de Tours, De virtutibus sancti Martini episcopi, II, 60: “...martyrium etiam uel in occultis insidiis uel in publicis iniuriis triumphabiliter adimpleuit".

52 Ibíd., I, 5: "Ipse est enim laus illius, cuius laus ab eius ore numquam recessit".

${ }^{53}$ Sylvie Labarre, en la introducción a la edición crítica de la Vita Martini de Paulino de Périgueux, explica cómo es posible encontrar distintos niveles de lectura. Además, se refiere a la ciudad de Tours bajo el concepto de "faro para la catolicidad", es decir, para la cristiandad latina (Labarre, ed., Paulino de Périgueux. Vie de saint Martin, 19-34).

${ }^{54} \mathrm{Al}$ respecto, véase a Heinzelmann, "La réécriture hagiographique dans l'œuvre de Grégoire de Tours", 23-37.
} 
se encuentra siempre presente y constituye, por ende, un antecedente directo del sentido pastoral y de la llamada al ejercicio de las virtudes de la obra literaria de Gregorio.

Así mismo aporta un elemento más a la correcta comprensión del modelo martiniano que él ha intentado proponer a partir de su propia experiencia como fiel cristiano, como obispo y como devoto del santo intercesor. Con relación a este punto, en el último tiempo, la profesora Boesch Gajano ${ }^{55}$ ha demostrado cómo la dinámica de la vida espiritual eremítica, particularmente retratada en el Vitae Patrum antes mencionado, permite comprender la propagación de los ideales de penitencia y de humildad, aspectos relevantes en toda la narración taumatúrgica del santo obispo de Tours.

Supuesto lo anterior, al momento de preguntarnos por el sentido que tendría el conocimiento de la verdadera sabiduría divina, cabe señalar que el principal objetivo del testimonio de la virtud del santo es la representación y manifestación de Cristo y de sus acciones entre los hombres. La presencia de la dimensión escatológica en la narración histórico-hagiográfica ${ }^{56}$, manifestada por medio de signos reales y maravillosos ${ }^{57}$, respondería a lo que podríamos llamar una anticipación profética del Reino.

Para Gregorio de Tours este tipo de sabiduría, característica inherente en el hombre de Dios, se haría evidente entre los fieles en la medida en que ellos buscan el seguimiento de Dios a través de una moral cristiana, con una vida evangélica manifestada de manera excelente en el discípulo Martín, quien viene a ser el eximio modelo del verdadero converso y el anticipador de las glorias celestes en este mundo ${ }^{58}$.

Consiguientemente, la labor de San Martín es presentada como la labor propia de los amici Dei a quienes se les rinde veneración porque ellos, que han sido verdaderamente fieles a su bautismo, participan de la vida sobrenatural pues han comprendido que la humildad se manifiesta por medio de un arrepentimiento real y de una corrección de vida, lo que suscita un acceso al verdadero conocimiento que consiste en la "ascensión hacia la santidad" 59 . Para Gregorio este sería, en definitiva, el sentido último de su catequesis de los milagros y su objetivo para con su grey, tal como se expresa al inicio del Libro IV:

\footnotetext{
${ }^{55}$ Cfr. Boesch Gajano, "Gregorio di Tours: scrittura della storia e storie di monaci”.

${ }^{56}$ Heinzelmann, “Grégoire de Tours et l'hagiographie mérovingienne”, 183.

${ }^{57}$ Cremascoli, "Il miracolo nell'agiografia di Gregorio Magno e di Gregorio di Tours”, 252.

${ }^{58}$ Isaïa, "La prophétie dans l'hagiographie latine du haut Moyen Âge (VIe-IXe siècle). L'histoire comme destin, prédestination et providence", 16.
}

${ }^{59}$ Labrousse, Saint Honorat. Fondateur de Lérins et évêque d'Arles, 71. 
...es, pues, manifiestamente claro para la inteligencia humana que no solamente aquellos que están exentos de crímenes, sino aun aquellos que han caído en el horror de un delito funesto, son exhortados a dar a los amigos de Dios un culto lleno de veneración. Este acto no solamente aprovecha en el mundo presente sino, más aún, es un consuelo para la vida futura. ${ }^{60}$

De este modo se podría entender cómo el acercamiento físico a la basílica de Tours, en primer lugar, o a las reliquias de San Martín, en el caso de que lo anterior no fuese posible, representaría tanto una peregrinación personal como -en un sentido también poético- un acercamiento al conocimiento de Cristo, constituyéndose por tanto en una suerte de epifanía en medio de una diócesis en la cual la emoción del cristiano prefiguraba, por medio de la experiencia personal y de las gestas divinas, el conocimiento de Dios y las mirabilia Dei.

En otros términos, el milagro trascendía la mera vivencia física que suponía la curación o el portento asociado a la sanación corporal y conducía al fiel cristiano a una experiencia catequética y espiritual característica de los bautizados.

En otro orden de cosas, Patrick Henriet ha escrito, al referirse a la obra de Gregorio Magno, que "ninguna santidad va sin espíritu profético", pues los santos "no ignoran el pensamiento de Dios" ${ }^{61}$. Por tanto, y si se tiene en consideración la contemporaneidad de los autores latinos, consideramos que dicha afirmación resultaría perfectamente aplicable al análisis del De uirtutibus sancti Martini episcopi, ya que Gregorio de Tours, en su deseo de acercamiento al mensaje evangélico, enseña con luz meridiana que no son los santos - ni siquiera el propio San Martín-quienes actúan con sus propias fuerzas, sino que es la gracia divina la que interviene por medio de ellos. $\mathrm{Al}$ modo del cuerpo místico de Cristo, los milagros obrados en la tierra corresponden únicamente a Dios: en sus palabras, "un solo Señor actúa por la virtud de un gran número de santos, y no se dividen en cuanto a su poder aquellos a quienes el Señor vuelve iguales en el cielo y similares en milagros sobre la tierra" ${ }^{\circ 2}$.

Además cabe mencionar que, para Gregorio, el hombre solo puede "restablecer la luz de la verdad”“3 por medio de un corazón contrito. Para ello es necesario vivir bajo

${ }^{60}$ Gregorio de Tours, De uirtutibus sancti Martini episcopi, IV, Prefacio: “...ergo perspicue patet intellectui humano, quod admoneantur quique non solum inmunes a crimine, uerum etiam noxialis criminis malo dediti, cultum reuerentes reddere amicis Dei. Quae res non solum in praesenti saeculo tribuit beneficium, uerum etiam praestat et refrigerium in futuro".

${ }^{61}$ Henriet, "Quod recte prophetia dicitur. Introduction”, 12.

${ }^{62}$ Gregorio de Tours, De uirtutibus sancti Martini episcopi, IV, 12: “...in multorum sanctorum uirtutibus unum Dominum operari, et nec illos disiunctos uirtutibus, quos caelo pares, miraculis Dominus aequales reddit in terris".

${ }^{63}$ Ibíd., II, 60: “...restituat mihi lumen ueritatis”. 
una disposición de ánimo que le permita reconocer, en su espíritu, la intervención de Dios por medio de la experiencia vital del prodigio divino. El milagro es, en definitiva, "un hecho interior" ${ }^{64}$ que puede manifestarse a los otros fieles -tal como lo menciona Giuseppe Cremascoli- y que se desprende y entiende a partir de la definición divina Deus caritas est (1Jn 4,16).

En dicho sentido, los milagros narrados en este compendio tienen relación directa con la devoción en un momento determinado - los años de Gregorio como obispo de la ciudad- y son atribuidos a la peregrinación y al patronazgo de este santo; es decir, estamos frente a un tiempo de santuarios ${ }^{65}$. Por eso, la visión personal y comunitaria antes referida se ve unida a la función tutora del protector, quien actúa en medio de los cristianos que buscan, arrepentidos de sus pecados, la voluntad de Dios.

Es así como la simple presencia de una reliquia o de un poco de tierra de la basílica de San Martín permiten la acción del santo, pues esta se asocia a una vida de virtud alejada de los adivinos y de las supersticiones, centrada solo en el poder omnipotente de Cristo. Gregorio lo expresa con las siguientes palabras: “...en efecto, un poco de polvo de la basílica vale más que los adivinos y sus medicamentos insensatos" ${ }^{66}$.

Un último aspecto por destacar es el sentido monástico que se puede apreciar en el conjunto de la obra, que en una primera lectura parecería una simple exposición redactada para los fieles laicos turonenses. Si bien esto resulta evidente, consideramos que el sentido explícito del De uirtutibus no impide, en modo alguno, la presencia de referencias a los ideales de una espiritualidad ascética, aunque quizás con menos asiduidad que las que han sido notadas en el Vitae Patrum o In gloria confessorum ${ }^{67}$.

De esta manera hemos de destacar que la máxima de la literatura monástica clásica, la que se puede resumir como una relación estrecha entre el relato ejemplar y la ortodoxia doctrinal ${ }^{68}$, aparece expuesta a lo largo de los cuatro libros que narran los milagros de San Martín. Este aspecto, sintetizado en el modelo del santo como ejemplodoctrina, se ve particularmente favorecido en la narración hagiográfica que pone el

\footnotetext{
${ }^{64}$ Cremascoli, "L'emozione del prodigio nel racconto dei 'Dialogi' di Gregorio Magno”, 230-233.

${ }^{65}$ Goullet y Philippart, "Le miracle médiéval. Bilan d'un colloque”, 11.

${ }^{66}$ Gregorio de Tours, De uirtutibus sancti Martini episcopi, I, 27: “...plus enim ualet parumper de puluere basilicae, quam illi cum medicamentis insaniae". Para una aproximación al tema de la magia, véase a Rousselle, Croire et guérir. La foi en Gaule dans l'Antiquité tardive, 104-105; Jiménez Sánchez y Maymó i Capdevila, "La magia en la Galia merovingia".

${ }^{67}$ Boesch Gajano, "Gregorio di Tours: scrittura della storia e storie di monaci", 81-92. Cabe mencionar, asÍ mismo, el Liber in gloria martyrum, del cual ha aparecido una reciente edición crítica en 2020.

${ }^{68}$ Cardelle de Hartmann, "Dialogue littéraire et récit exemplaire dans la littérature monastique de Sulpice Sévère à Grégoire le Grand”, 65.
} 
acento en el testimonio didáctico de los portentos contemporáneos y que entiende todo el trabajo de escritura como una auténtica predicación y una concreción, así mismo, del ejercicio de la práctica episcopal por medio de la labor como historiador ${ }^{69}$.

En relación con el punto anterior, la cuestión de la figura del obispo como culmen sanctitatis, tal como lo ha señalado Boesch Gajano ${ }^{70}$ para la época en estudio, aparecería representada por medio de una doble dimensión, dado que, por una parte, estaríamos frente a un prelado -Gregorio- que, como resultado de la herencia de su diócesis y del proyecto pastoral a su cargo, presenta a San Martín en cuanto modelo de santidad; por otro lado, este sería propuesto como un modelo insigne de vida ascética y de retiro del mundo, aspectos importantes que ya hemos mencionado a la hora de analizar cómo la curación y la salvación operan en el individuo de manera personal y comunitaria.

Cabe hacer notar que las referencias a estos ideales de vida retirada se orientarían más bien a los fieles laicos y a la comunidad de bautizados y no a una comunidad específica, es decir, no habría un sentido regulador de la célula monástica o de la vida cenobítica, como sería el caso de otros autores contemporáneos del Mediodía galo: Cesáreo de Arlés, por ejemplo. En otros términos, el ideal del santo-protector (el obispo) es aquel que prima en la sociedad cristiana merovingia en la cual Gregorio vive y es este el que le sirve para actualizar la historia santa que él desea escribir.

Aun al reconocer lo expuesto, nos parece importante manifestar que la representación del obispo en cuanto pastor de los fieles no se opone, necesariamente, al ideal monástico en cuanto ascesis, sino más bien muestra una mutación del ideal de retiro cenobítico del siglo $\mathrm{V}^{71}$. Si bien no encontramos los elementos propiamente monásticos que identifican de modo particular, por ejemplo, la búsqueda del silencio y del apartamiento del mundo como aparece en la Vita Martini de Sulpicio, sí es posible identificar la integridad espiritual de San Martín, que Gregorio -sin ser monje- quiere destacar por medio de la acción milagrosa y de las enseñanzas a los cristianos de sus días.

La caridad, la castidad, la humildad y la paciencia son virtudes que de una u otra forma se encuentran representadas tanto en las acciones del intercesor como en las

${ }^{69}$ Labarre, "Les saints guérisseurs et protecteurs chez Grégoire de Tours et Venance Fortunat", 325; Salvador Ventura, "El obispo como historiador", 268.

${ }^{70}$ Boesch Gajano. "Gregorio di Tours: scrittura della storia e storie di monaci”, 90.

${ }^{71}$ Sylvie Labarre ha mostrado la evolución del ideal martiniano desde las biografías de Sulpicio hasta la poesía hagiográfica del siglo VI. Ella ha puesto en relieve la tenue referencia a la vida en Marmoutier en la época de Fortunato y Gregorio, con el fin de acentuar la labor intercesora y episcopal del santo (Labarre, "Aux sources du monachisme martinien, les Vies de Martin en prose et en vers", 39). 
conversiones y enseñanzas aprendidas por los creyentes beneficiados por los milagros del santo del Loira;es decir, ellas devienen en una suerte de iniciación a la vida cristiana.

La relevancia de la figura del santo-obispo no supone, desde nuestro punto de vista, una oposición al ascetismo monástico ${ }^{72}$, sino -por el contrario- lo refuerza por medio de una expansión de los ideales de silencio, oración y penitencia que se extienden de manera protectora entre los fieles cristianos. A modo de ejemplo, el relato en verso de la Vita Martini de Venancio Fortunato - poeta y amigo de Gregoriopresenta una imagen cada vez más contemplativa de un San Martín entendido como un mediador celeste ${ }^{73}$, lo cual aparece reflejado en la prosa de nuestro autor, quien de una u otra forma refuerza la idea del ascetismo como característica de la narración ejemplar propuesta en el De uirtutibus ${ }^{74}$. Esto, a su vez, hace eco de la hagiografía latina del siglo VI, la cual sigue representando una de las ramas literarias más influenciadas por la espiritualidad ascética, a pesar de sus particularidades en la Galia merovingia ${ }^{75}$.

De esta manera, los distintos favores obrados por el santo y presentados por Gregorio a lo largo de los cuatro libros conducirían al lector de la época a una meditación de los fundamentos de la espiritualidad cristiana y le permitirían tener frente a sí el ejemplo del hombre que, habiendo superado la tentación del pecado, es identificado como un verdadero patronus y amico $D e i^{76}$ que puede obrar milagros por la virtud divina.

En relación con este punto y a propósito de los trazos de Gregorio de Tours en Gregorio Magno, Adalbert de Vogüé ha sugerido ${ }^{77}$, a partir de la lectura de algunas de las obras del doctor romano, la presencia de un fundamento espiritual, y quizás catequético, en la hagiografía del obispo de Tours. Así, el análisis de este conjunto de narraciones portentosas deja en evidencia la necesidad del mérito de la oración privada y de la eficacia de la penitencia, tal como lo hemos visto, y permiten descubrir

\footnotetext{
${ }^{72}$ Bruno Judic menciona cómo la difusión del culto a San Martín se asocia, a partir del conocimiento del texto de Sulpicio en Italia, a la promoción del ascetismo y de la vida monástica. Él sugiere la presencia del modelo martiniano en la figura de San Benito y en los Diálogos de Gregorio Magno (Judic, "Les modèles martiniens dans le christianisme des Ve-VIIe siècles", 96-99).

${ }^{73}$ Labarre, "Lévolution du modèle d'homme et de chrétien incarné par Martin du IVe au Vie siècle", 28-29. 74 "...as a narrator he spoke in ascetic language" (Leyser, "Divine Power Flowed from this Book: Ascetic Language and Episcopal Authority in Gregory of Tours' Life of the Fathers", 284).

${ }^{75}$ Heinzelmann, "Studia sanctorum. Éducation, milieux d'instruction et valeurs éducatives dans l'hagiographie en Gaule jusqu’à la fin de l'époque mérovingienne”, 129.

${ }^{76}$ Heinzelmann, "The Works of Gregory of Tours and Patristic Tradition”, 168.

${ }_{77}$ De Vogüé, “Grégoire le Grand, lecteur de Grégoire de Tours ?”, 229.
} 
eventuales reminiscencias de la vida ascética como modelo de vida perfecta y prefiguración del orden divino ${ }^{78}$.

La acción del santo -en este caso San Martín- emana de Dios y solo puede operar en el arrepentido, dándose así la dinámica de purificación-sanación física unida a la conversión del espíritu. A modo de ejemplo, el letrado turonense nos cuenta en primera persona que en medio de un viaje sufrió fuertes dolores de cabeza, los cuales fueron curados gracias a la acción milagrosa de las reliquias de San Martín, las mismas que él osa llamar "purgatorio celeste" ${ }^{79}$. Ellas le permitieron sanarse de los males físicos para, una vez reconocida la acción divina, purgar sus pecados y limpiar su alma como cristiano.

En suma, nuestro obispo galorromano querría mostrar cómo la acción de San Martín opera en el día a día por medio de la purificación del alma y de una verdadera conversión del espíritu, porque el santo varón e intercesor "lava las manchas de las conciencias" ${ }^{\prime \prime}$.

\section{A modo de conclusión}

$\mathrm{Al}$ momento de hacer un balance respecto de la literatura latino-cristiana del siglo VI, la figura de Gregorio de Tours resulta fundamental. En su esfuerzo y vocación hagiográfica, los cuatro libros reunidos en el De uirtutibus sancti Martini constituyen un compendio de un valor histórico inestimable, pues en ellos es posible ver acrisolado en el tiempo la cosmovisión religiosa de una comunidad eclesial inserta en la Galia merovingia. El milagro aparece representado como una suerte de bálsamo de Dios que actúa en la historia humana y que, a través de la intercesión del santo patrono, viene a ser la manifestación más plena de la virtud cristiana.

Para nuestro autor, la práctica de su labor pastoral también se ejercía por medio de la narración hagiográfica, la que adquiere una dimensión narrativo-catequética que tiene la capacidad de suscitar y promover la conversión y la consecuente iniciación a la vida cristiana. A falta de catecismos, la presentación del milagro como hecho histórico providente deviene en una experiencia espiritual basada en el cumplimiento -ya en la

\footnotetext{
${ }^{78} \mathrm{El}$ ascetismo monástico es uno de los principales ideales propuestos desde Oriente durante el siglo IV. Tiempo más tarde los monjes adquirieron un prestigio particular en Occidente, y en el siglo VI se consagró, por ejemplo, al primer monje-obispo de Roma (Gregorio Magno). Para una visión general del paradigma "monje obispo", consúltese a Villegas Marín, "El obispo y los monjes".

${ }^{79}$ Gregorio de Tours, De uirtutibus sancti Martini episcopi, III, 60: “...purgatorium caeleste”.

${ }^{80}$ Ibíd., III, 60: “...ipsas illas conscientiarum maculas abstergit ac leuigat”.
} 
tierra- de las promesas del Evangelio por medio del ejemplo y acción del obispo-asceta Martín, modelo de fidelidad y de seguimiento de Cristo ${ }^{81}$.

$\mathrm{Al}$ sentido ejemplar de este compendio de portentos se une un sentido catequético y doctrinal. El hombre de Iglesia, Gregorio, da testimonio del santo de la ciudad y su relato se torna un sermón encarnado en donde la acción del intercesor conlleva toda una enseńanza de los fundamentos de la fe y del camino espiritual del bautizado. Por eso, la acción del portento estaría determinada, en primer lugar, por un arrepentimiento y una práctica penitencial que se vería reflejada, después de la sanación, en un testimonio y servicio comunitario para alabanza a Dios en medio de los hombres. Esta manifestación sobrenatural -el milagro-constituiría una anticipación de las glorias celestes las cuales, dispensadas por medio de las maravillas obradas por intercesión del santo, serían una anticipación de la Jerusalén eterna.

En síntesis, San Martín opera en nombre de Cristo y su acción pastoral desde su santuario-basílica, por medio de los prodigios, pone la atención en el conocimiento del Señor y en la humildad cristiana como virtud fundamental para la ascensión en la vida del espíritu. El fiel de la época, exhortado por medio de las intervenciones divinas cotidianas, ve cómo el hombre virtuoso actúa en nombre de Dios, y es puente de los beneficios que el Señor entrega a quienes siguen una vida según las enseñanzas bíblicas.

En otros términos, es el ideal evangélico que Gregorio nos expresa refiriéndose al santo del Loira en el Prefacio del Libro IV, con las siguientes palabras: “... un amigo de Dios, quien nos ha devuelto la mayor parte del tiempo a la salud cuando estábamos agobiados por tan graves enfermedades" ${ }^{\prime 2}$.

Así, el verdadero poder de San Martín radicaría, entonces, en el ideal de oración privada pues por medio de ella se lograría el contacto con la verdadera sabiduría que emana del Espíritu y que propicia una perfecta imitatio Christi; allí estaría, sin dudas, el ideal ascético-monástico que no se opondría al modelo del obispo sino, por el contrario, lo reforzaría y le daría un sentido de excelencia cristiana para los bautizados por medio del ejemplo.

En resumen, el escritor de Tours tendría por objetivo legar un tratado testimonial de milagros con un fin catequético-moral y espiritual, pero así mismo con un sentido de alabanza de las mirabilia Dei de sus días; por eso, su testimonio de hombre de fe no deja indiferente al lector de cualquier época.

\footnotetext{
${ }^{81}$ Heinzelmann, "Pouvoir et idéologie dans l'hagiographie mérovingienne", 50-53.

${ }^{82}$ Gregorio de Tours, De uirtutibus sancti Martini episcopi, IV, Prefacio: “....amicum Dei, qui, tantis in nos morborum obpressis generibus, plerumque restituit sanitati”.
} 


\section{Referencias}

Aguirre Durán, Marcelo. "Gregorio de Tours y la hagiografía del siglo VI. Aproximaciones histórico-teológicas al libro Sobre las virtudes de San Martín”. Anuario de Historia de la Iglesia 29 (2020): 293-310.

Beaujard, Brigitte. Le culte des saints en Gaule. Les premiers temps. D'Hilaire de Poitiers à la fin du Vie siècle. París: Du Cerf, 2000.

Boesch Gajano, Sofia. "Gregorio di Tours: scrittura della storia e storie di monaci". Adamantius 17 (2011): 81-92.

. "Spazi del meraviglioso nell'alto medioevo latino". En Aspetti del meraviglioso nelle letterature medievali. Medioevo latino, romanzo, germánico e céltico, por Franca Ela Consolino y otros, 23-34. Turnhout: Brepols, 2016.

Bouyer, Louis. Le sens de la vie monastique. París: Du Cerf, 2008.

Brown, Peter. El culto a los santos. Su desarrollo y su función en el cristianismo latino. Salamanca: Sígueme, 2018.

. Through the Eye of a Needle. Wealth, the Fall of Rome, and the Making of Christianity in the West, 350-550 AD. Princeton (NJ): Princeton University Press, 2012.

Cardelle de Hartmann, Carmen. "Dialogue littéraire et récit exemplaire dans la littérature monastique de Sulpice Sévère à Grégoire le Grand”. En Formes dialoguées dans la literature exemplaire du Moyen Âge, por Marie Anne Polo de Beaulieu, 55-68. París: Honoré de Champion Éditeur, 2012.

Cremascoli, Giuseppe. "Il miracolo nell'agiografia di Gregorio Magno e di Gregorio di Tours". En Gregorio Magno e l'agiografia fra IV e VII secolo, por Antonella Degl'Innocenti y otros, 245-256. Florencia: Sismel-Edizioni del Galluzzo, 2007. - "Lemozione del prodigio nel racconto dei 'Dialogi' di Gregorio Magno". Benedictina. Rivista del Centro Storico Benedettino Italiano 65 (2018): 229-236.

De Vogüé, Adalbert (ed.). Grégoire le Grand. Dialogues I. París: Du Cerf, 1978.

. "Grégoire le Grand, lecteur de Grégoire de Tours ?" Analecta Bollandiana 94 (1976): 225-233.

Dumézil, Bruno. "Des évêques locaux aux saints civiques en Gaule". En Des dieux civiques aux saints patrons (IVe-VIIe siècle), por Jean-Pierre Caillet y otros, 185-197. París: Picard, 2015.

Fontaine, Jacques (ed.). Sulpice Sévère. Vie de Saint Martin I. París: Du Cerf, 2004. 
Goullet, Monique, y Guy Philippart. "Le miracle médiéval. Bilan d'un colloque”. En Miracles, vies et réécritures dans l'Occident médiéval, por M. Goullet y Martin Heinzelmann, 9-20. Ostfildern : Jan Thorbecke Verlag, 2006.

Gregorio de Tours. Historiarum libri X. Editado por Bruno Krusch, MGH. Hanover: Hahn, 1951.

. Liber In gloria Martyrum. Editado por Luce Pietri. París: Les Belles Lettres, 2020.

. Liber Vitae Patrum. Editado por Luce Pietri. París: Les Belles Lettres, 2016.

. De uirtutibus sancti Martini episcopi, Libri I-IV. Editado por Bruno Krusch, MGH. Hanover: Hahn, 1885.

Heinzelmann, Martin. “Grégoire de Tours et l'hagiographie mérovingienne”. En Gregorio Magno e l'agiografia fra IV e VII secolo, por Antonella Degl'Innocenti y otros, 155-192. Florencia: Sismel-Edizioni del Galluzzo, 2007.

- "La réécriture hagiographique dans l'œuvre de Grégoire de Tours". Beihefte der Francia 58 (2003): 15-70.

. "Pouvoir et idéologie dans l'hagiographie mérovingienne". En Hagiographie, idéologie et politique au Moyen Âge en Occident, por Edina Bozóky, 37-58. Turnhout: Brepols, 2012.

. "Studia sanctorum. Éducation, milieux d'instruction et valeurs éducatives dans l'hagiographie en Gaule jusqu'à la fin de l'époque mérovingienne”. En Haut Moyen-Âge. Culture, éducation et sociét. Études offertes à Pierre Riché, por Michel Sot, 105-138. Nanterre et la Garenne-Colombes: Publidix y Éditions Européennes Érasme, 1990.

- "The Works of Gregory of Tours and Patristic Tradition". En A Companion to Gregory of Tours, por Alexander Callander Murray, 281-336. Leiden: Brill, 2016.

Henriet, Patrick. "Quod recte prophetia dicitur. Introduction". En Hagiographie et prophétie (Vie-XIIIe siècles), por P. Henriet y otros, 3-13. Florencia: Edizioni del Galluzzo, 2017.

Isaïa, Marie-Céline. "La prophétie dans l'hagiographie latine du haut Moyen Âge (Vie-IXe siècle). L'histoire comme destin, prédestination et providence". En Hagiographie et prophétie (Ve-XIIIe siècles), por Patrick Henriet y otros, 15-49. Florencia: Edizioni del Galluzzo, 2017. 
Jiménez Sánchez, Juan Antonio, y Pere Maymó i Capdevila. "La magia en la Galia merovingia”. Espacio, tiempo y forma. Serie II. Historia Antigua 30 (2017): 183-204.

Judic, Bruno. "Les modèles martiniens dans le christianisme des Ve-VIIe siècles". En L'empreinte chrétienne en Gaule du IVe au IXe siècle, por Michèle Gaillard, 91-109. Turnhout: Brepols, 2014.

. "Les origines du culte de Saint Martin de Tours aux Ve et VIe siècles". En La figure de saint Martin de Tours. Patrimoine, histoire. L'exemple de l'Ain, dirigido por Joël Lambert, 13-24. Bourg-en-Bresse: Société Nouvelle Gorini, 2010.

Labarre, Sylvie. "Aux sources du monachisme martinien, les Vies de Martin en prose et en vers". Annales de Bretagne et des Pays de l'Ouest 119 (2012): 27-40. . "La figure de Saint Martin chez Grégoire de Tours". En Un nouveau Martin. Essor et renouveaux de la figure de saint Martin IVe-XXIe siècle, por Bruno Judic y otros, 205-215. Tours: Presses Universitaires François Rabelais, 2019. - "L'évolution du modèle d'homme et de chrétien incarné par Martin du IVe au Vie siècle". En Avec les Pères de l'Église, penser l'homme devant Dieu. Figures d'hier, questions d'aujourd'hui, por Isabelle Bochet y Michel Fédou, II, 17-29. París: Mediasèvres, 2002.

. "L'expression du divin dans l'hagiographie de Venance Fortunat et de Grégoire de Tours". Hagiographica XXV (2018): 37-56.

- "Les saints guérisseurs et protecteurs chez Grégoire de Tours et Venance Fortunat". En Des dieux civiques aux saints patrons (IVe-VIIe siècle), por Jean-Pierre Caillet y otros, 315-325. París: Éditions Picard, 2015.

Labarre, Sylvie (ed.). Paulino de Périgueux. Vie de saint Martin. París: Du Cerf, 2016.

Labrousse, Mireille. Saint Honorat. Fondateur de Lérins et évêque d'Arles. Bégrollesen-Mauges: Abbaye de Bellefontaine, 1995.

Leyser, Conrad. "Divine Power Flowed from this Book: Ascetic Language and Episcopal Authority in Gregory of Tours' Life of the Fathers". En The World of Gregory of Tours, por Mitchell, Kathleen e Ian Wood, 281-294. Leiden: Brill, 2002.

Madec, Goulven (ed). Saint Augustin. La première catéchèse (De catechizandis rudibus). París: Institut d'Études Augustiniennes, 2001. 
Philippart, Guy. "L'hagiographie, histoire sainte des amis de Dieu". En Hagiographies. Histoire internationale de la littérature hagiographique latine et vernaculaire en Occident des origines à 1550, por G. Philippart, IV, 13-40. Turnhout: Brepols, 2006.

Pietri, Luce. La ville de Tours du IVe au VIe siècle. Naissance d'une cité chrétienne. Roma: École Française de Rome, 1983.

- "Quand et comment Martin de Tours est-il devenu le saint patron par excellence de la Gaule ?”. En Des dieux civiques aux saints patrons (IVe-VIIe siècle), por Jean-Pierre Caillet y otros, 353-364. París: Picard, 2015.

Pietri, Luce, y Marc Heijmans. Prosopographie chrétienne du Bas-Empire. Prosopographie de la Gaule chrétienne (314-614), I. París: Association des Amis du Centre d'Histoire et Civilisation de Byzance, 2013.

Rousselle, Aline. Croire et guérir. La foi en Gaule dans l'Antiquité tardive. París: Fayard, 1990.

Salvador Ventura, Francisco. "El obispo como historiador". En El obispo en la Antigüedad tardía. Homenaje a Ramón Teja, por Silvia Acerbi y otros, 259-272. Madrid: Trotta, 2016.

Van Dam, Raymond. Saints and Their Miracles in Late Antique Gaul. Princeton (NJ): Princeton University Press, 1993.

Villegas Marín, Raúl. "El obispo y los monjes”. En El obispo en la Antigüedad tardía. Homenaje a Ramón Teja, por Silvia Acerbi y otros, 317-334. Madrid: Trotta, 2016. 